University of Montana

ScholarWorks at University of Montana

4-2004

\title{
Avian Life-History Evolution Has an Eminent Past: Does it Have a Bright Future?
}

Thomas E. Martin

University of Montana - Missoula, tom.martin@umontana.edu

Follow this and additional works at: https://scholarworks.umt.edu/wildbio_pubs

Part of the Life Sciences Commons

Let us know how access to this document benefits you.

\section{Recommended Citation}

Martin, Thomas E., "Avian Life-History Evolution Has an Eminent Past: Does it Have a Bright Future?" (2004). Wildlife Biology Faculty Publications. 34.

https://scholarworks.umt.edu/wildbio_pubs/34

This Editorial is brought to you for free and open access by the Wildlife Biology at ScholarWorks at University of Montana. It has been accepted for inclusion in Wildlife Biology Faculty Publications by an authorized administrator of ScholarWorks at University of Montana. For more information, please contact scholarworks@mso.umt.edu. 


\title{
The Auk
}

A Quarterly

Journal of Ornithology

Vol. 121 No. 2 April 2004

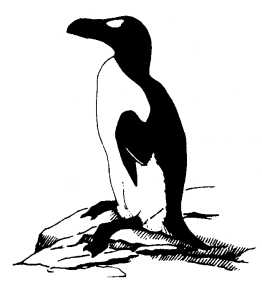

The Auk 121(2):289-301, 2004

\section{PERSPECTIVES IN ORNITHOLOGY}

\section{AVIAN LIFE-HISTORY EVOLUTION HAS AN EMINENT PAST: DOES IT HAVE A BRIGHT FUTURE?}

\author{
Thomas E. Martin ${ }^{1}$ \\ U.S. Geological Survey Biological Resources Discipline, Montana Cooperative Wildlife Research Unit, Avian Studies \\ Program, University of Montana, Missoula, Montana 59812, USA
}

Avian Life-history evolution has an eminent past (Moreau 1944; Lack 1948, 1954, 1968; Skutch 1949), because birds played a critical role in the early development of life-history theory (Partridge and Harvey 1988). Those early investigators focused on clutch-size variation and described not only broad patterns of worldwide variation in clutch sizes, but also outlined a variety of hypotheses to explain that variation, including food limitation, nest predation, and adult mortality (Moreau 1944, Lack 1948, Skutch 1949). Despite the early description of broad geographical patterns and alternative hypotheses, subsequent attention focused on north-temperate systems and food limitation.

Life-history evolution continues to be an area of active investigation among ornithologists, but I believe progress has been retarded because we remain fixed on three historical foci: (1) clutch-size evolution, (2) food limitation, and (3) north-temperate systems (and possibly an even narrower subset of northern strategies given a common focus on hole-nesting birds). Those focal points can be traced to the strong influence of David Lack on life-history studies in birds (i.e. Lack 1948, 1954, 1968). Lack energized an important field of investigation and made significant historical contributions to

${ }^{1}$ E-mail: tom.martin@umontana.edu thinking about components of those issues. Yet, we often remain transfixed on those three foci and conduct tests at the wrong level (i.e. a proximate level) to understand evolution of life-history variation. Recognizing the pitfalls of those issues and moving beyond them is needed for a progressive future in avian life-history theory.

\section{Problems with Food-Limitation Concepts And Tests}

A focus on clutch size and the potential importance of food has been perpetuated in part by continually repeated brood-size manipulations in attempts to examine those issues. Indeed, an enormous number $(>100)$ of papers have been published using brood-size manipulations to examine energy and food limitations on clutch-size evolution. However, brood-size manipulations examine phenotypic plasticity and proximate responses, rather than addressing ultimate (evolutionary) causes of clutch-size variation. A focus on whether individuals modify clutch size in response to variation in food resources, or modify effort with manipulation of brood size, is a proximate question (i.e. it examines immediate responses). Certainly, selection can drive the evolution of phenotypic plasticity, or reaction norms. For example, food limitation clearly occurs in nature (e.g. see review in Martin 1987), and 
phenotypic plasticity in clutch sizes among years or territories of differing food availability can be adaptive, as suggested by the individual optimization hypothesis (e.g. Pettifor et al. 1988, 2001). Tests of that hypothesis can yield critical information on the adaptive basis of both variation in clutch size among individuals and plasticity of clutch size within individuals. Further, it can allow estimation of the form or slope of reaction norms in response to variation in food, and a focus on why the form or slope of the reaction norm varies among species or populations is a very interesting evolutionary question (e.g. Fig. 1).

On the other hand, although variation in food or physiological condition can yield adaptive shifts in optima (i.e. reaction norms), such shifts do not test whether food is the evolutionary cause of the central tendency of a trait; they do not address why (i.e. ultimate causes) the mean and range of clutch sizes in species $A$ are less than in species B, or why species B expends a much greater proportion of available energy compared with species A (Fig. 1). For example, why has a Ruby-crowned Kinglet (Regulus calendula) evolved a clutch size of 8-12 eggs, when a Yellow-rumped Warbler (Dendroica coronata) feeding in the same habitat and locations has a clutch size of 3-5 eggs? Can kinglets find so much additional food in the same habitat with similar foraging methods that they can raise $2-2.5 \times$ as many young as Yellow-rumped Warblers? Moreover, if kinglets were gathering that much more food, would not selection act rapidly on Yellow-rumped Warblers to feed on those same foods and sources, if they could get such significant gains in fecundity? Consider further that clutch size of Yellowrumped Warblers varies only 1-2 eggs over the extreme range of environmental conditions that they occupy across their extensive geographic range (see Martin 1988) and remains half or less of the clutch size of kinglets. Is the variation in food abundance encountered by Yellowrumped Warblers across habitats and the North American continent really less than the difference between kinglets and Yellow-rumped Warblers feeding in the same habitat? I would say the answer to these questions is "no," and the importance of food as the primary driver of evolutionary differences in clutch size must be questioned. Indeed, Yellow-rumped Warblers never increase clutch size to one typical of

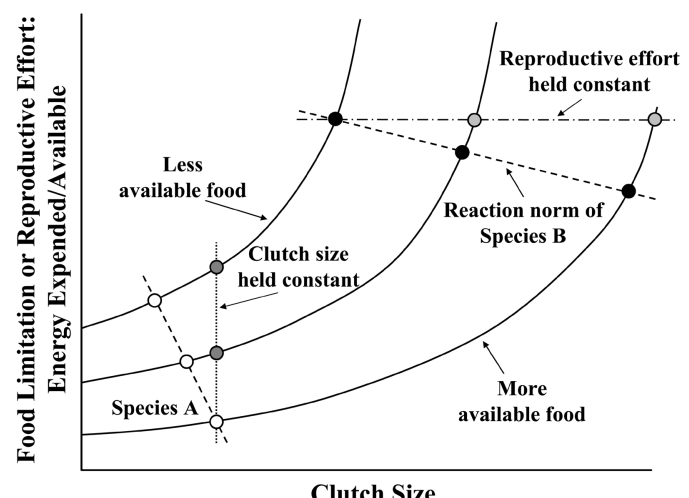

FIg. 1. Relationship of food limitation and reproductive effort to clutch size as a function of varying food availability. Food limitation can be defined on the basis of food need (energy expenditure) relative to food availability, which also defines reproductive effort. Food limitation and reproductive effort increase with clutch size for a given food availability (single curve). Increased food availability (three solid curves) decreases food limitation for a given clutch size (dotted line). Reaction norms (dashed lines) reflect phenotypic adjustments in clutch size to variation in food availability for a given genotype. Clutch size can be increased with food availability without increasing reproductive effort (dashed and dotted line). Clutch size can also increase with food availability while simultaneously decreasing reproductive effort (dashed lines). The slope of these reaction norms may differ among species. Some species (e.g. species A) may save more of the extra energy from additional food for self-maintenance (i.e. increased residual reproductive value) by increasing clutch size a small amount to obtain a greater reduction in reproductive effort, whereas other species may put relatively more of the greater energy available into current reproductive effort and save less (i.e. species B) or none (dotted and dashed line) for future reproduction. Critical questions that need to be answered include: (1) How do slopes and forms of reaction norms vary among species? (2) Why do the slopes of reaction norms differ among species? (3) Why does one species (e.g. species B) invest more available energy in current reproduction compared with another species (e.g. species A)? These same questions could be asked within species if we knew genotypes.

kinglets (i.e. 8 eggs) regardless of how much food is available, which suggests that food is not the primary cause for the difference. Of course, kinglets and Yellow-rumped Warblers are in different avian families; but those kinds of differences occur across many phylogenetic groups and even closely related species, 
emphasizing that evolution of clutch-size differences among phylogenetic lineages can not be easily explained by food (Martin 1988, 1995).

The inability of food availability to explain many inter-specific clutch-size differences is further supported by reproductive effort theory and the commonly observed inverse relationship between clutch size and adult survival across species (Sæther 1988; Martin 1995, 2002; Ghalambor and Martin 2001). Adult survival is thought to decrease with increasing reproductive effort, as reflected by increased clutch size (Williams 1966a, b; Hirshfield and Tinkle 1975; Reznick 1985; Roff 1992). Reproductive effort is defined as the proportion of available energy expended on reproduction. Available energy for small passerines with limited storage capacity is largely determined by food availability in the environment. Energy expenditure (as reflected by clutch size) can then increase with food (energy) availability without increasing reproductive effort (Fig. 1). Thus, fecundity can increase with food availability without decreasing adult survival (Hirshfield and Tinkle 1975, Rose and Charlesworth 1981, Lande 1982, Tuomi et al. 1983, Reznick 1985), or even yielding a positive relationship between clutch size and adult survival (e.g. Högstedt 1981, Smith 1981, Pettifor et al. 1988). Such results conflict with the observed inverse relationship between clutch size and survival (i.e. Sæther 1988, Martin 1995, Ghalambor and Martin 2001).

Those results make perfect sense in the context of selection for iteroparity from early mortality. Early mortality, as commonly faced by birds from nest predation (Ricklefs 1969; Martin 1992, 1993), favors strategies that increase chances of iteroparity (Murphy 1968, Hirshfield and Tinkle 1975, Law 1979, Michod 1979). Selection for increased iteroparity should favor increases in clutch size with food availability to levels that do not compromise survival and iteroparity opportunities (i.e. reaction norm slopes $\leq 0$ in Fig. 1; see Hirshfield and Tinkle 1975, Michod 1979), yielding the common observations that fecundity increases with food availability without decreasing adult survival (see above). Yet, we are still left with the critical questions of why reaction norm slopes differ among species, and why species differ in the relative amount of available energy invested in fecundity for a given level of food availability (e.g. species B vs. species A along a single curve in Fig. 1).
Traditional Life-history Theory

An alternative perspective that may better explain observed patterns comes from traditional life-history theory (e.g. Murphy 1968, Hirshfield and Tinkle 1975, Law 1979, Michod 1979, Charlesworth 1980, Lande 1982). Assume that passerine species (I will restrict comments to passerines because additional complexities come into play when considering a broader range of taxa) have access to relatively similar amounts of food (i.e. a single curve in Fig. 1). Selection from other environmental factors can favor differential allocation of energy to reproductive effort (current reproductive value) versus maintenance (residual reproductive value) for similar energy availability (Williams 1966a, Murphy 1968, Hirshfield and Tinkle 1975, Law 1979, Michod 1979). For example, consider the very likely possibility that two species like kinglets and Yellowrumped Warblers that feed on similar food sources in the same habitat have access to similar levels of food. Some other source of environmental selection has potentially acted on kinglets to allocate relatively more energy to current reproduction (i.e. higher reproductive effort) and less to future reproduction. In contrast, selection has favored relatively greater allocation of resources to future reproduction and less to current reproduction in Yellow-rumped Warblers. Consequently, a future focus on alternative selection pressures that drive variation in allocation to current (i.e. reproductive effort) versus future reproduction might yield greater gains in understanding the evolution of life-history variation among species.

The idea that selection has favored the evolution of specific levels of reproductive effort can potentially explain the results of brood manipulation studies. Effort, as measured by doubly-labeled water, often is not strongly influenced by brood size or other manipulations (e.g. Bryant and Westerterp 1983; Moreno 1989; Moreno et al. 1995, 1999; Verhulst and Tinbergen 1997; but see Deerenberg et al. 1995). If selection favors evolution of a particular balance of current (e.g. parental effort) versus residual (survival) reproductive value (Williams 1966b), then adults should not exhibit a proximate response to manipulations and modify current effort to compromise residual reproductive value. Instead, parents should pass more of the costs on to their young. The more commonly 
TABLE 1. Examples of life-history variation among a suite of traits for two species along slow and fast gradients that are representative of the extremes of the gradient and two species that are closely related and of similar body mass.

\begin{tabular}{|c|c|c|c|c|}
\hline \multirow[b]{2}{*}{ Species ${ }^{a}$} & \multicolumn{2}{|c|}{ Extremes of the gradient } & \multicolumn{2}{|c|}{ Emberizids of similar mass } \\
\hline & $\begin{array}{c}\text { (Fast) } \\
\text { Ruby-crowned } \\
\text { Kinglet }\end{array}$ & $\begin{array}{l}\text { (Slow) } \\
\text { Northern } \\
\text { Fulmar }\end{array}$ & $\begin{array}{c}\text { (Fast) } \\
\text { Green-tailed } \\
\text { Towhee }\end{array}$ & $\begin{array}{l}(\text { Slow }) \\
\text { Stripe-headed } \\
\text { Brush-Finch }\end{array}$ \\
\hline Mass (g) & 5.7 & 665 & 30 & 33 \\
\hline Clutch size (number of eggs) & 10 & 1 & 4 & 2 \\
\hline Age of first reproduction (years) & 1 & 7-12 & 1 & $?$ \\
\hline Frequency of reproduction & $3-4 \times$ year $^{-1}$ & $1 \times$ year $^{-1}$ & $4-7 \times$ year $^{-1}$ & $4-6 \times$ year $^{-1}$ \\
\hline Adult mortality probability & 0.72 & 0.03 & 0.46 & 0.10 \\
\hline Incubation period $(\mathrm{d})$ & 15 & 48 & 12 & 16 \\
\hline Parental care duration & Short & Long & Short & Long \\
\hline
\end{tabular}

a Species: Ruby-crowned Kinglet (Regulus calendula), Northern Fulmar (Fulmarus glacialis), Green-tailed Towhee (Pipilo chlorurus), Stripe-headed Brush-Finch (Buarremon torquatus; note as a further extreme that B. brunneinuncha has a clutch size of 1 egg and an incubation period of 18 days).

observed increases in mortality or weight loss in young rather than increases in adult mortality with manipulations (e.g. Martin 1987, Linden and Møller 1989, Moreno et al. 1999) fit such predictions. In short, brood manipulations do not differentiate between birds being unable to raise more young or being "unwilling" to increase effort and risk of mortality because of evolved strategies.

Responses should vary along a gradient, such that species with high chances of survival and future reproduction should pass more costs on to their young than species with lower adult survival and chances of breeding again (Ghalambor and Martin 2001, Martin 2002). Thus, for example, we might expect a steeper reaction norm in species with high survival than in species with lower survival (e.g. species A vs. species B, respectively, in Fig. 1). A comparative brood manipulation study could provide a strong test of such possibilities; the extent of costs that parents accept themselves (reduced renesting probability or future clutch size, reduced adult survival) versus the costs that they pass on to their offspring (reduced growth rates, smaller fledging size, increased nestling mortality) could be examined with brood-size manipulations among related species with differing prospects of future reproduction (i.e. differing adult survival).

\section{North-temperate Systems versus Geographic Variation in Life Histories}

Life histories are composed of a much broader suite of traits than simply clutch size and adult survival, and those traits tend to covary along slow and fast gradients (Table 1; see Promislow and Harvey 1990; Martin 1995, 2002). Lifehistory variation can reflect allometric effects of mass (Sæther 1987, 1989) that explain some differences, but even closely related species of similar mass can show major differences along this slow and fast gradient (Table 1). Such differences are typical of north-temperate versus tropical and southern hemisphere locations (e.g. Tables 1 and 2).

Many of our existing perspectives and tests of life-history evolution are based on northtemperate systems (i.e. Lack 1948, 1954, 1968; Stearns 1976), which include $<25 \%$ of the bird species of the world. Most species on earth live in the tropics and southern hemisphere. Southern hemisphere species commonly exhibit life-history traits similar to tropical species, and both differ from north-temperate species.

TABLE 2. Generalized description of life-history variation among a suite of traits along slow and fast gradients that also reflect differences between north-temperate versus southern (tropical and southern hemisphere) species. This represents a gradient and variation exists within each of these gradient ends.

\begin{tabular}{lcc}
\hline & Fast & Slow \\
\hline Clutch size & Large & Small \\
Egg mass & Smaller & Larger \\
Age of first reproduction & Early & Late \\
$\begin{array}{l}\text { Frequency of with-year } \\
\quad \text { reproduction }\end{array}$ & Variable & Variable \\
Adult mortality probability & High & Low \\
$\begin{array}{l}\text { Developmental rate } \\
\text { Parental care duration }\end{array}$ & Fast & Slow \\
\hline
\end{tabular}


For example, clutch size does not differ between equatorial and south-temperate Africa within $60 \%$ of species, although it increases for some (Moreau 1944). Those species that show increases in clutch size with latitude to the south show much smaller increases than in the north (Moreau 1944, Yom-Tov 1987, Yom-Tov et al. 1994, Martin 1996, Martin et al. 2000). Thus, life-history strategies of tropical and southern hemisphere birds differ markedly from northtemperate birds (Tables 1 and 2); that is, smaller clutch size, greater egg mass, greater adult survival, slower development, lower metabolism, and later age of first reproduction in southern species, even when compared with phylogenetically related northern species (Moreau 1944; Skutch 1949; Ricklefs 1976, 1992; Rowley and Russell 1991; König and Gwinner 1995; Martin et al. 2000; Ghalambor and Martin 2001; Martin 2002; Wikelski et al. 2003). Given that northtemperate species represent a minor proportion of the species of the world with life histories that deviate from the majority of species of the world, we need to ask: Are north-temperate species the appropriate models for understanding avian life-history evolution in general?

Use of north-temperate areas as a model for understanding life-history evolution is appropriate only if the relative influence of processes are the same as in the rest of the world. If not, then an understanding of the relative importance of processes in other regions is needed to better understand avian life-history evolution and to gain further insight into why north-temperate species are different. A return to the geographic focus of early investigators may advance our understanding of life-history evolution, because it removes focus from the minority group of northern species with one subset of life-history strategies and places it in a new context. For example, many coexisting species of tropical passerines have the same clutch size of two eggs. What is the likelihood that this incredible diversity of species encounter similar levels of food or nest predation to explain clutch size? The point becomes even clearer when considered in an elevational context: both food abundance and nest predation rates vary among elevations in the tropics (Janzen 1973, Skutch 1985, Janes 1994), yet clutch size remains at two for many species across elevations (Skutch 1954, 1981). Neither food nor nest predation can explain clutch sizes of many tropical species (Martin 1996, Martin et al. 2000). These quick examples suggest that two major explanations of life-history variation in north-temperate systems (i.e. food limitation and nest predation) cannot alone explain broad geographical life-history variation and emphasize that (1) north-temperate systems may not be appropriate general models and (2) other alternatives must be explored.

\section{Clutch Size versus Other Life-history Traits}

Examination of alternative hypotheses has been complicated by the common focus on clutch size (for which I am equally guilty). Clutch size is a major component of reproductive effort that confuses considerations of clutch size and survival relationships: Is high adult mortality an intrinsic cost of high reproductive effort, or is high reproductive effort favored by high extrinsic adult mortality? Because clutch size represents a major component of reproductive effort, which can influence adult mortality, those two alternatives become difficult to untangle. Yet, understanding those opposing causal pathways has important implications for understanding and examining evolution of variation in avian life histories.

One potential solution is to shift focus to other life-history traits (Martin 2002). As mentioned, many life-history traits (clutch size, egg mass, developmental rate, parental care behavior, age of first reproduction, adult survival) differ between southern and northern species (Tables 1 and 2). By focusing on traits that are influenced by, but represent a smaller proportion of, reproductive effort, we can reduce the extreme confounding between reproductive effort and survival seen with clutch size. In addition, we can remove some of our biases and focus on new questions and hypotheses. For example, why are developmental rates slower in the south? Why does incubation behavior and the role of males vary among species and geographic locations? Why is egg mass greater in the south? Why are numbers of feeding visits by parents so high in some southern species and so low in others? Feeding visits can be negatively related to nest-predation risk (Martin et al. 2000), whereas nestling growth rates can be positively related to it (Bosque and Bosque 1995, Remeš and Martin 2002). How can growth rates increase when parents feed less often? 


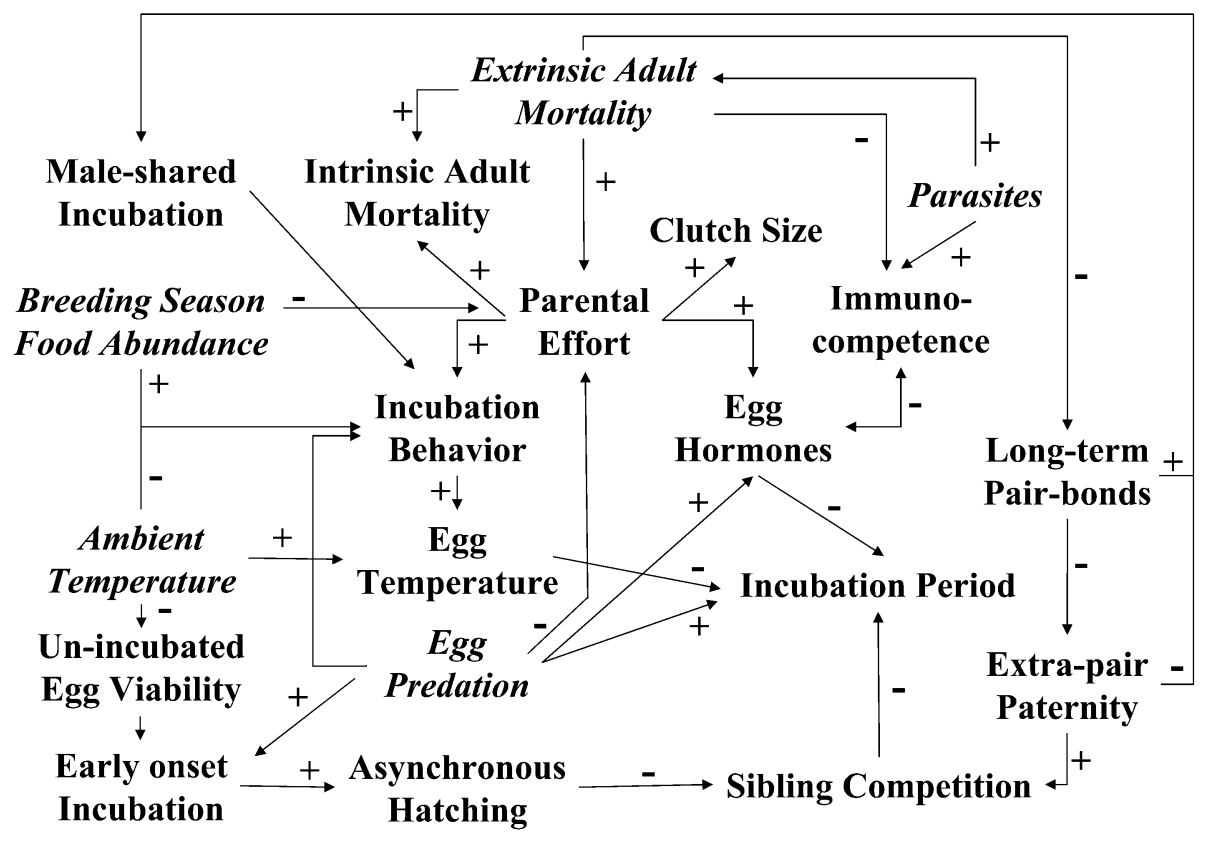

FIG. 2. Hypothesized relationships among selected life-history traits related to incubation, environmental selection pressures, and proximate mechanisms of variation in trait expression. Environmental sources of selection are in italic. Hypothesized direction of relationships are reflected by "+" and "- - ", where "+" reflects positive covariation and "-" reflects an inverse relationship.

Most traits interact to influence each other through trade-offs. Taking a broad life-history approach to understanding trait variation may provide important insights into understanding trait evolution in different fields of investigation (Figs. 2 and 3). For example, evolutionary developmental biology is a major field of investigation (Hall 1992, Gilbert 2001), and causes of the evolution of differing development rates and strategies remains an open question. Studies of developmental rates have demonstrated important physiological constraints and trade-offs (Ricklefs 1968, Starck and Ricklefs 1998, West et al. 2001; see Gilbert 2001). Slower development during incubation (Fig. 2) may allow enhanced development of the immune system (Ricklefs 1992, 1993; Brommer 2004) or morphological components that influence locomotor performance and predation vulnerability (Billerbeck et al. 2001, Lankford et al. 2001, Shine and Olsson 2003). As a result, selection from parasites may influence development of the immune system (e.g. Ricklefs 1992), whereas variation from predation risk may influence differential development of locomotor modules that affect escape prospects (Dial 2003a, b). Resulting trade-offs then influence development rates and strategies (Figs. 2 and 3).

Trade-offs among internal components are not the only influence on developmental rates. Parental care behavior, such as incubation behavior, may also play a major role in creating variation in developmental rates and periods (Martin 2002). Incubation behavior may shift proximately with variation in food and ambient temperature (White and Kinney 1974, Haftorn 1983, Weathers and Sullivan 1989, Sanz 1996). Yet species may evolve different levels of incubation effort independent of food and temperature (Martin 2002), and variation in incubation effort has important implications for development. If slower development results from cooler embryo temperatures because of lower parental effort (Martin 2002), then locomotor performance or immune function may not be enhanced by the slower development. In other words, slow development in tropical regions may be an unavoidable consequence of selection favoring reduced parental effort, rather than an adaptive offspring trait. By considering the complex 


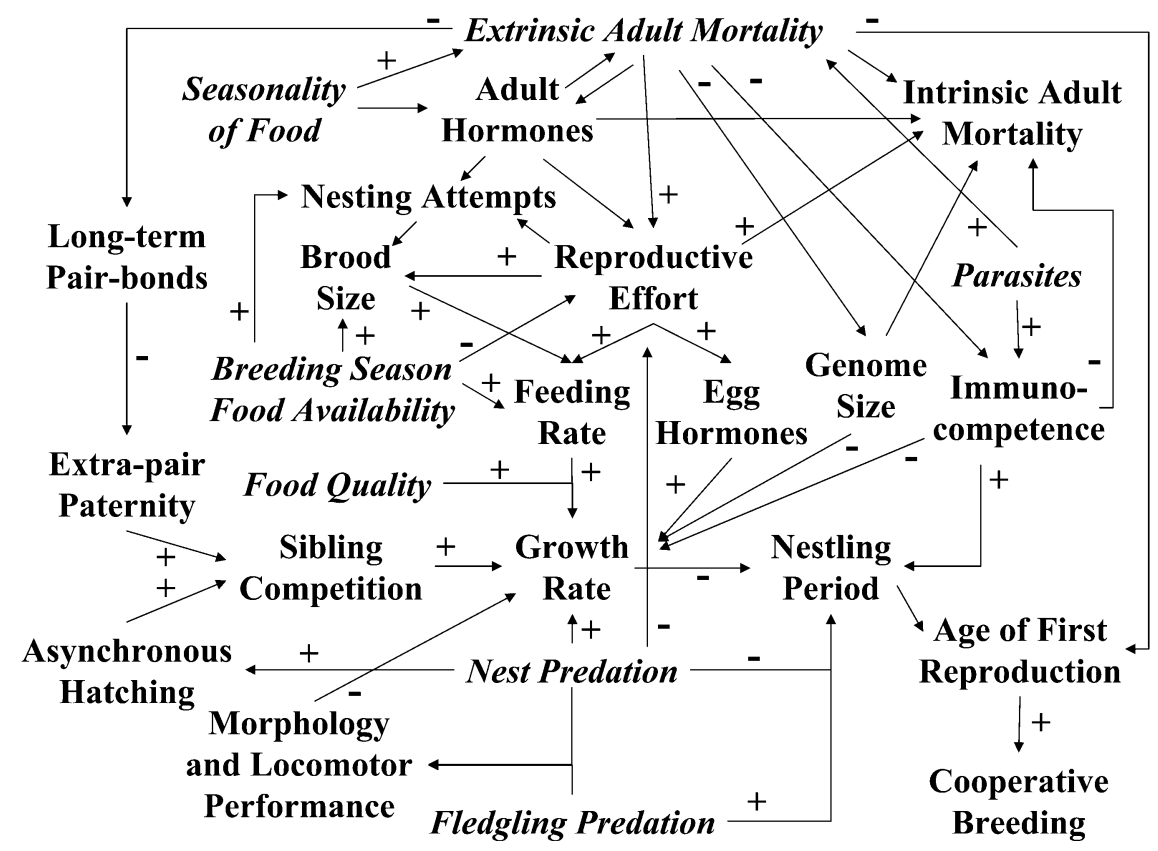

FIG. 3. Hypothesized relationships among selected life-history traits related to the nestling period, environmental selection pressures, and proximate mechanisms of variation in trait expression. Environmental sources of selection are in italic. Hypothesized direction of relationships are reflected by "+" and "-", where " +" reflects positive covariation and "-" reflects an inverse relationship.

linkages that may occur among diverse traits of broad life-history strategies (Figs. 2 and 3), we can bring new perspectives to understanding their variation.

Flight is another example of the kinds of complex linkages that may occur. Flight is thought to reduce risk of predation mortality, which may explain why flying organisms have delayed onset of senescence, even though they have increased metabolic rate (Williams 1957, Partridge and Barton 1993, Holmes and Austad 1995). Genome size also is argued to decrease in better flyers (Tiersch and Wachtel 1991, Hughes and Hughes 1995; but see Waltari and Edwards 2002); and genome size has been possibly linked to longevity (Monaghan and Metcalfe 2000; but see Morand and Ricklefs 2001), development time (Olmo et al. 1989, Morand and Ricklefs 2001), and metabolic rate (Vinogradov 1997). Development time is related to adult mortality (Ricklefs 1993, Martin 2002), and adult mortality (and senescence) is linked to fecundity (Sæther 1988; Martin 1995, 2002; Ghalambor and Martin 2001), and both vary with latitude (Martin 2002). Recognizing and exploring this complex array of linkages (Figs. 2 and 3) can yield new hypotheses and insights into the mechanisms and causes of life-history variation.

Social behavior is another major field of investigation (Rubenstein and Wrangham 1986, Ligon 1999) that could be an integrated component of life-history strategies. For example, low adult mortality may favor cooperative breeding (Fig. 3) in combination with other ecological constraints and perhaps by also influencing age of first reproduction (Arnold and Owens 1999, Hatchwell and Komdeur 2000; but see Cockburn 2003). Variation in adult mortality could also influence duration of pair bonds, because increased adult mortality increases the probability of needing to find a new mate (see Sæther 1986, Choudhury 1995). Strength and duration of pair bonds may also influence the extent that males share incubation, which varies extensively among species and remains poorly understood (Skutch 1957, Lack 1968, Bart and Tornes 1989, Kleindorfer et al. 1995, Kleindorfer and Hoi 1997). Differences in pair bond duration and parental care contributions of males might be associated with sperm competition or extrapair paternity (e.g. see Møller and Cuervo 2000). Extrapair paternity, in turn, might 
influence sibling competition and development rates (Ricklefs 1993, Royle et al. 1999, Lloyd and Martin 2003). In short, integration of a broad suite of phenotypic traits into a life-history framework (Figs. 2 and 3) may yield important new insights into individual traits and highlight alternative hypotheses for investigation.

\section{Age-specific Mortality}

Ornithologists have focused on the idea that food drives reproductive effort, which drives adult mortality. However, many lifehistory models and theory (Murphy 1968, Schaffer 1974, Hirshfield and Tinkle 1975, Law 1979, Michod 1979) argue that selection from age-specific mortality can drive evolution of reproductive effort, rather than the converse. Furthermore, a number of empirical studies in taxa other than birds have verified this theory that age-specific mortality can drive life-history evolution (e.g. Reznick and Bryga 1987; Reznick et al. 1990, 1996; Crowl and Covich 1990; Roff 1992). Do we really believe that birds are different from other taxa? I do not, and many of the relationships discussed above could potentially be explained by age-specific mortality. I believe that a focus on age-specific mortality as drivers of avian life-history evolution (e.g. Figs. 2 and 3) could move the field forward.

Nearly a decade ago, I found that one component of age-specific mortality (i.e. nest predation) explained significant amounts of north-temperate life histories (Martin 1995). However, the value of conducting broad examinations of geographic variation in life histories was later emphasized to me: I realized that nest predation could not explain broad latitudinal variation in lifehistory traits (Martin 1996, 2002; Martin et al. 2000). Application of standardized field protocols to test ideas across broad geographic areas provides rigorous examination of their generality. I believe that life-history theory focused on age-specific mortality, together with broad studies of geographic variation in avian life histories, holds great promise for improving our understanding of avian life-history variation.

Variation in extrinsic adult mortality can drive variation in reproductive effort (Murphy 1968; Hirshfield and Tinkle 1975; Law 1979; Michod 1979; Reznick and Bryga 1987; Crowl and Covich 1990; Reznick et al. 1990, 1996). In particular, high adult mortality can favor increased reproductive effort, even with costs of reproduction on survival, to increase chances of producing more offspring before mortality occurs. Note that reproductive effort can cause intrinsic mortality through the cost of reproduction (e.g. Williams 1966a, b; Roff 1992), although extrinsic mortality may also influence intrinsic mortality (see Fig. 2) through effects on senescence (Medawar 1952; Williams 1957, 1966a, b; Rose 1991; Holmes and Austad 1995). The extent to which intrinsic mortality approaches or exceeds extrinsic mortality may be influenced by the extent and variability of juvenile (nest) mortality (Fig. 2). High and variable nest mortality will increase the benefits of iteroparity, because increased number of reproductive attempts can increase chances of reproducing during a more favorable period (Murphy 1968, Hirshfield and Tinkle 1975, Law 1979, Michod 1979). Consequently, high and variable nest mortality can favor a level of reproductive effort where intrinsic adult mortality does not exceed extrinsic adult mortality to thereby enhance residual reproductive value. In contrast, either low or constant juvenile mortality or both can favor increased reproductive effort, where intrinsic adult mortality exceeds extrinsic adult mortality such that residual reproductive value is sacrificed for current reproduction. Both responses, however, are also influenced by the relative levels and variability of extrinsic adult mortality. The interplay between adult and juvenile mortality on iteroparity was emphasized in Charnov and Schaffer's (1973) resolution to Cole's (1954) paradox and was developed further in later life-history models (e.g. Schaffer 1974, Law 1979, Michod 1979).

Those ideas and models are relevant to birds, because extrinsic sources of both adult and juvenile mortality can be expected to vary among species and geographic regions. For example, birds that breed in north-temperate zones have two options for winter: to overwinter in the north where cold temperatures increase energy demands when food abundance is quite low or to migrate to the south and face the high mortality risks of moving long distances through unknown and sometimes inhospitable habitats. The potential mortality consequences of migration were emphasized by the long-term studies of Sillett and Holmes (2002), who found that most adult mortality occurred during migration. In contrast, tropical and southern- 
hemisphere species have sufficient food and sufficiently moderate temperatures to allow permanent residency and familiarity with food sources and refuges so as to minimize mortality risks (see Rowley and Russell 1991). These points are highlighted in comparisons of nonbreeding birds in northern systems with breeding birds in southern systems; adult survival probability for nonbreeding (recently widowed) males of two tit species (Parus spp.) are slightly increased over breeding individuals, which suggests a cost of reproduction (see Ekman and Askenmo 1986), but the survival rate of those nonbreeding individuals is still less than typical territorial, breeding birds in the south (e.g. see Sandercock et al. 2000, Martin 2002). The lower survival of nonbreeding northern birds compared with breeding southern birds clearly indicates that breeding costs are not the major cause of latitudinal differences in adult survival and that extrinsic costs are more important. Those latitudinal differences in extrinsic adult mortality could then serve as major drivers of latitudinal variation in life histories, although again tempered by variation in nest mortality (Martin 2002; see Figs. 2 and 3).

For example, clutch size varied with nest predation within regions, but not between northern and southern latitudes (Martin et al. 2000). That could reflect the interplay of adult and nest mortality: lower extrinsic adult mortality in southern locations could favor lower reproductive effort in general (smaller clutch sizes, reduced incubation attentiveness) compared with northern locations, but variation in nest predation among species within each latitude can yield adjustments to those broader differences (Fig. 4). At the same time, recall the earlier discussion that nest predation does not explain clutch size variation among elevations within the tropics. The result may reflect tradeoffs and interaction of additional traits. In particular, low adult mortality may favor reduced effort to enhance between-season iteroparity, whereas nest predation may favor increased within-season iteroparity (numbers of broods and nesting attempts; see Martin 1995), which may be particularly important in tropical locations. The latter point serves to emphasize the potential interplay of a broad suite of interactive phenotypic traits that may respond to variation in age-specific mortality and trade-offs with each other (Figs. 2 and 3).

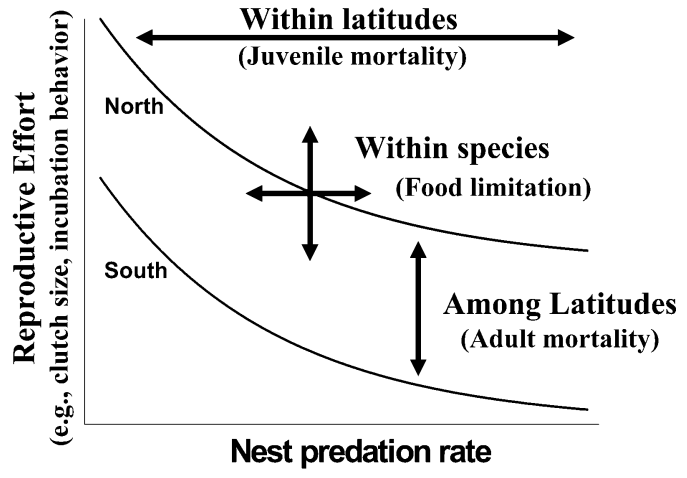

FIG. 4. A hypothesis of the major environmental influences on latitudinal variation in life histories. A decrease in adult mortality in southern latitudes compared with the north favors generally reduced reproductive effort. Variation in nest predation among species and nest sites favors variation within latitudes; lower nest mortality favors increased reproductive effort for a given level of adult mortality. Variation in food allows adjustments (i.e. reaction norms; see Fig. $1)$, particularly within species. All three factors can work at all levels (e.g. nest predation can contribute to differences among latitudes), but the primary effects are indicated by arrowed bars.

We have a broad array of ultimate and proximate mechanistic hypotheses (e.g. Figs. 2 and 3) available for testing to identify new linkages and insights into avian life-history variation in the future. Moreover, life-history traits are critical components of fitness. Thus, study of lifehistory evolution is arguably essential to understanding evolution of phenotypic expression in general. Avian life-history theory has had an eminent past. A future that moves to examining alternative hypotheses, suites of traits and their inter-linkages, and geographic locations beyond north-temperate systems holds the bright potential of a leading role for birds in further advancing life-history theory and understanding.

\section{Acknowledgments}

I am grateful to J. J. Fontaine and P. Lloyd for helpful comments on this manuscript. I gratefully acknowledge the funding support of NSF (DEB-9981527, INT-9906030) for my geographic life-history work.

\section{Literature Cited}

Arnold, K. E., And I. P. F. Owens. 1999. Cooperative breeding in birds: The role of ecology. Behavioral Ecology 10:465-471. 
BART, J., AND A. Tornes. 1989. Importance of monogamous male birds in determining reproductive success. Behavioral Ecology and Sociobiology 24:109-116.

Billerbeck, J. M., T. E. LANkford, JR., AND D. O. Conover. 2001. Evolution of intrinsic growth and energy acquisition rates. I. Trade-offs with swimming performance in Menidia menidia. Evolution 55:1863-1872.

Bosque, C., And M. T. Bosque. 1995. Nest predation as a selective factor in the evolution of developmental rates in altricial birds. American Naturalist 145:234-260.

Brommer, J. E. 2004. Immunocompetence and its costs during development: An experimental study in Blue Tit nestlings. Proceedings of the Royal Society of London, Series B (Supplement) 271:S110-S113.

Bryant, D. M., and K. R. Westerp. 1983. Time and energy limits to brood size in House Martins Delichon urbica. Journal of Animal Ecology 52: 905-925.

Charlesworth, B. 1980. Evolution in Age-structured Populations. Cambridge University Press, Cambridge, United Kingdom.

Charnov, E. L., and W. M. Schaffer. 1973. Life history consequences of natural selection: Cole's result revisited. American Naturalist 107:791-793.

Choudhury, S. 1995. Divorce in birds: A review of the hypotheses. Animal Behaviour 50:413-429.

Cockburn, A. 2003. Cooperative breeding in oscine passerines: Does sociality inhibit speciation? Proceedings of the Royal Society of London, Series B 270:2207-2214.

Cole, L. C. 1954. The population consequences of life history phenomena. Quarterly Review of Biology 29:103-137.

Crowl, T. A., And A. P. Covich. 1990. Predatorinduced life-history shifts in a freshwater snail. Science 247:949-951.

Deerenberg, C., I. Pen, C. Dijkstra, B.-J. Arkies, G. H. Visser, ANd S. DAan. 1995. Parental energy expenditure in relation to manipulated brood size in the European Kestrel Falco tinnunculus. Zoology (Jena) 99:39-48.

Dial, K. P. 2003a. Wing-assisted incline running and the evolution of flight. Science 299: 402-404.

Dial, K. P. 2003b. Evolution of avian locomotion: Correlates of flight style, locomotor modules, nesting biology, body size, development, and the origin of flapping flight. Auk 120:1-12.

Ekman, J., and C. Askenmo. 1986. Reproductive cost, age-specific survival and a comparison of the reproductive strategy in two European tits (genus Parus). Evolution 40:159-168.

Ghalambor, C. K., And T. E. Martin. 2001.
Fecundity-survival trade-offs and parental risk-taking in birds. Science 292:494-497.

Gilbert, S. F. 2001. Ecological developmental biology: Developmental biology meets the real world. Developmental Biology 233:1-12.

Haftorn, S. 1983. Egg temperature during incubation in the Great Tit Parus major, in relation to ambient temperature, time of day, and other factors. Fauna Norvegica, Series C 6:22-38.

Hall, B. K. 1992. Evolutionary Developmental Biology. Chapman and Hall, London.

Hatchwell, B. J., ANd J. Komdeur. 2000. Ecological constraints, life history traits, and the evolution of cooperative breeding. Animal Behaviour 59: 1079-1086.

Hirshfield, M. F., And D. Tinkle. 1975. Natural selection and the evolution of reproductive effort. Proceedings of the National Academy of Sciences USA 72:2227-2231.

Högstedt, G. 1981. Should there be a positive or negative correlation between survival of adults in a bird population and their clutch size? American Naturalist 118:568-571.

Holmes, D. J., and S. N. Austad. 1995. The evolution of avian senescence patterns: Implications for understanding primary aging processes. American Zoologist 35:307-317.

Hughes, A. L., And M. K. Hughes. 1995. Small genomes for better flyers. Nature 377:391.

JANES, S. W. 1994. Variation in the species composition and mean body size of an avian foliagegleaning guild along an elevational gradient: Correlation with arthropod body size. Oecologia 98:369-378.

JANZEN, D. 1973. Sweep samples of tropical foliage insects: Effects of seasons, vegetation types, elevation, time of day, and insularity. Ecology 54:687-708.

Kleindorfer, S., B. Fessl, and H. Hoi. 1995. More is not always better: Male incubation in two Acrocephalus warblers. Behaviour 132:607-625.

Kleindorfer, S., ANd H. Hoi. 1997. Nest predation avoidance: An alternative explanation for male incubation in Acrocephalus melanopogon. Ethology 103:619-631.

König, S., And E. Gwinner. 1995. Frequency and timing of successive broods in captive African and European stonechats Saxicola torquata axillaris and S. t. rubicola. Journal of Avian Biology 26:247-254.

LACK, D. 1948. The significance of clutch size. Part 3. Some interspecific comparisons. Ibis 90:25-45.

LACK, D. 1954. The Natural Regulation of Animal Numbers. Clarendon Press, Oxford.

LACK, D. 1968. Ecological Adaptations for Breeding in Birds. Methuen, London.

LANDE, R. 1982. A quantitative genetic theory of life history evolution. Ecology 63:607-615. 
LAnkford, T. E., JR., J. M. Billerbeck, and D. O. Conover. 2001. Evolution of intrinsic growth and energy acquisition rates. II. Trade-offs with vulnerability to predation in Menidia menidia. Evolution 55:1873-1881.

LAw, R. 1979. Optimal life histories under agespecific predation. American Naturalist 114: 399-417.

Ligon, J. D. 1999. The Evolution of Avian Breeding Systems. Oxford University Press, New York.

Linden, M., And A. P. Møller. 1989. Cost of reproduction and covariation of life history traits in birds. Trends in Ecology and Evolution 4: 367-371.

Lloyd, J., ANd T. E. Martin. 2003. Sibling competition and pre-natal development in birds. Proceedings of the Royal Society of London, Series B 270:735-740.

Martin, T. E. 1987. Food as a limit on breeding birds: A life-history perspective. Annual Review of Ecology and Systematics 18:453-487.

Martin, T. E. 1988. Nest placement: Implications for selected life history traits, with special reference to clutch size. American Naturalist 132: 900-910.

Martin, T. E. 1992. Breeding productivity considerations: What are the appropriate habitat features for management? Pages 455-473 in Ecology and Conservation of Neotropical Migrants (J. M. Hagan III and D. W. Johnston, Eds.). Smithsonian Institution Press, Washington, D.C.

Martin, T. E. 1993. Nest predation among vegetation layers and habitat types: Revising the dogmas. American Naturalist 141:897-913.

Martin, T. E. 1995. Avian life history evolution in relation to nest sites, nest predation, and food. Ecological Monographs 65:101-127.

Martin, T. E. 1996. Life history evolution in tropical and south temperate birds: What do we really know? Journal of Avian Biology 27: 263-272.

Martin, T. E. 2002. A new view for avian life history evolution tested on an incubation paradox. Proceedings of the Royal Society of London, Series B 269:309-316.

Martin, T. E., P. R. Martin, C. R. Olson, B. J. Heidinger, and J. J. Fontaine. 2000. Parental care and clutch sizes in North and South American birds. Science 287:1482-1485.

Medawar, P. B. 1952. An Unsolved Problem of Biology. H. K. Lewis and Co. Ltd., London.

Michod, R. E. 1979. Evolution of life histories in response to age-specific mortality factors. American Naturalist 113:531-550.

Møller, A. P., And J. J. Cuervo. 2000. The evolution of paternity and paternal care in birds. Behavioral Ecology 11:472-485.
Monaghan, P., and N. B. Metcalfe. 2000. Genome size and longevity. Trends in Genetics 16: 331-332.

Morand, S., And R. E. Ricklefs. 2001. Genome size, longevity, and development time in birds. Trends in Genetics 17:567-568.

Moreau, R. E. 1944. Clutch size: A comparative study, with reference to African birds. Ibis 86 : 286-347.

Moreno, J. 1989. Variation in daily energy expenditure in nesting Northern Wheatears (Oenanthe oenanthe). Auk 106:18-25.

Moreno, J., R. J. Cowie, J. J. Sanz, and R. S. R. Williams. 1995. Differential response by males and females to brood manipulations in the Pied Flycatcher: Energy expenditure and nestling diet. Journal of Animal Ecology 64: 721-732.

Moreno, J., S. Merino, J. Potti, A. de León, and R. RoDríQuez. 1999. Maternal energy expenditure does not change with flight costs or food availability in the Pied Flycatcher (Ficedula hypoleuca): Costs and benefits for nestlings. Behavioral Ecology and Sociobiology 46:244-251.

Murphy, G. I. 1968. Pattern in life history and the environment. American Naturalist 102: 391-403.

Olmo, E., T. Capriglione, and G. Odierna. 1989. Genome size evolution in vertebrates: Trends and constraints. Comparative Biochemistry and Physiology 92B:447-453.

Partridge, L., and N. H. Barton. 1993. Optimality, mutation and the evolution of aging. Nature 362:305-311.

Partridge, L., and P. H. Harvey. 1988. The ecological context of life history evolution. Science 241:1449-1455.

Pettifor, R. A., C. M. Perrins, and R. H. McCleery. 1988. Individual optimization of clutch size in Great Tits. Nature 336:360-362.

Pettifor, R. A., C. M. Perrins, and R. H. McCleery. 2001. The individual optimization of fitness: Variation in reproductive output, including clutch size, mean nestling mass and offspring recruitment, in manipulated broods of Great Tits Parus major. Journal of Animal Ecology 70:62-69.

Promislow, D. E. L., And P. H. Harvey. 1990. Living fast and dying young: A comparative analysis of life-history variation among mammals. Journal of Zoology (London) 220:417-437.

Remeš, V., AND T. E. Martin. 2002. Environmental influences on the evolution of growth and developmental rates in passerines. Evolution 56: 2505-2518.

Reznick, D. 1985. Costs of reproduction: An evaluation of the empirical evidence. Oikos 44:257-267. 
Reznick, D. A., And H. Bryga. 1987. Life-history evolution in guppies (Poecilia reticulata): 1. Phenotypic and genetic changes in an introduction experiment. Evolution 41:1370- 1385.

Reznick, D. A., H. Bryga, And J. A. Endler. 1990. Experimentally induced life-history evolution in a natural population. Nature 346:357-359.

Reznick, D. A., M. J. Butler IV, F. H. Rodd, And P. Ross. 1996. Life-history evolution in guppies (Poecilia reticulata) 6. Differential mortality as a mechanism for natural selection. Evolution 50:1651-1660.

Ricklefs, R. E. 1968. Patterns of growth in birds. Ibis 110:419-451.

Ricklefs, R. E. 1969. An analysis of nesting mortality in birds. Smithsonian Contributions in Zoology, no. 9.

Ricklefs, R. E. 1976. Growth rates of birds in the humid New World tropics. Ibis 118:179- 207.

Ricklefs, R. E. 1992. Embryonic development period and the prevalence of avian blood parasites. Proceedings of the National Academy of Sciences USA 89:4722-4725.

Ricklefs, R. E. 1993. Sibling competition, hatching asynchrony, incubation period, and lifespan in altricial birds. Current Ornithology 11: 199-276.

Roff, D. A. 1992. The Evolution of Life Histories. Chapman and Hall Publishers, London.

Rose, M. R. 1991. Evolutionary Biology of Aging. Oxford University Press, New York.

Rose, M. R., and B. Charlesworth. 1981. Genetics of life history in Drosophila melanogaster, I. Sib analysis of adult females. Genetics 97:173-186.

Royle, N. J., I. R. Hartley, I. P. F. Owens, and G. A. PArker. 1999. Sibling competition and the evolution of growth rates in birds. Proceedings of the Royal Society of London, Series B 266: 923-932.

Rowley, I., And E. Russell. 1991. Demography of passerines in the temperate southern hemisphere. Pages 22-44 in Bird Population Studies: Relevance to Conservation and Management (C. M. Perrins, J.-D. Lebreton, and G. J. M. Hirons, Eds.). Oxford University Press, New York.

Rubenstein, D. I., and R. W. Wrangham. 1986. Ecological Aspects of Social Evolution. Princeton University Press, Princeton, New Jersey.

SÆther, B.-E. 1986. Life history correlates of promiscuous mating systems: When to be a good father. Oikos 47:125-127.

SÆther, B.-E. 1987. The influence of body weight on the covariation between reproductive traits in European birds. Oikos 48:79-88.

SÆther, B.-E. 1988. Pattern of covariation between life-history traits of European birds. Nature 331:616-617.
SÆther, B.-E. 1989. Survival rates in relation to body weight in European birds. Ornis Scandinavica 20:13-21.

SANDERCock, B. K., S. R. Beissinger, S. H. Stoleson, R. R. Melland, and C. R. Hughes. 2000. Survival rates of a Neotropical parrot: Implications for latitudinal comparisons of avian demography. Ecology 81:1351-1370.

SANZ, J. J. 1996. Effect of food availability on incubation period in the Pied Flycatcher (Ficedula hypoleuca). Auk 113:249-253.

Schaffer, W. M. 1974. Optimal reproductive effort in fluctuating environments. American Naturalist 108:783-790.

Shine, R., And M. Olsson. 2003. When to be born? Prolonged pregnancy or incubation enhances locomotor performance in neonatal lizards (Scincidae). Journal of Evolutionary Biology 16:823-832.

Sillett, T. S., AND R. T. Holmes. 2002. Variation in survivorship of a migratory songbird throughout its annual cycle. Journal of Animal Ecology 71:296-308.

Skutch, A. F. 1949. Do tropical birds rear as many young as they can nourish? Ibis 91:430- 455.

SKUTCH, A. F. 1954. Life histories of Central American birds. Pacific Coast Avifauna, no. 31.

Sкuтсн, A. F. 1957. The incubation patterns of birds. Ibis 99:69-93.

Sкutch, A. F. 1981. New studies of tropical American birds. Publications of the Nuttall Ornithological Club, no. 19.

Sкuтch, A. F. 1985. Clutch size, nesting success, and predation on nests of Neotropical birds, reviewed. Ornithological Monographs 36: 575-594.

Sмith, J. N. M. 1981. Does high fecundity reduce survival in Song Sparrows? Evolution 35: 1142-1148.

Starck, J. M., and R. E. Ricklefs, Eds. 1998. Avian Growth and Development. Oxford University Press, New York.

Stearns, S. C. 1976. Life-history tactics: A review of the ideas. Quarterly Review of Biology 51:3-47.

Tiersch, T. R., AND S. S. Wachtel. 1991. On the evolution of genome size in birds. Journal of Heredity 82:363-368.

Tuomi, J., T. Hakala, and E. Haukioja. 1983. Alternative concepts of reproductive efforts, costs of reproduction, and selection in life history evolution. American Zoologist 23:25-34.

Verhulst, S., And J. M. Tinbergen. 1997. Clutch size and parental effort in the Great Tit Parus major. Ardea 85:111-126.

Vinogradov, A. E. 1997. Nucleotypic effect in homeotherms: Body-mass independent resting metabolic rate of passerine birds is related to genome size. Evolution 51:220-225. 
Waltari, E., ANd S. V. Edwards. 2002. Evolutionary dynamics of intron size, genome size, and physiological correlates in Archosaurs. American Naturalist 160:539-552.

Weathers, W. W., and K. A. Sullivan. 1989. Nest attentiveness and egg temperature in the Yellow-eyed Junco. Condor 91:628-633.

West, G. B., J. H. Brown, And B. J. Enquist. 2001. A general model for ontogenetic growth. Nature 413:628-631.

White, F. N., And J. L. Kinney. 1974. Avian incubation. Science 186:107-115.

Wikelski, M., L. Spinney, W. Schelsky, A. Scheuerlein, and E. Gwinner. 2003. Slow pace of life in tropical sedentary birds: A commongarden experiment on four stonechat populations from different latitudes. Proceedings of the Royal Society of London, Series B 270: 2383-2388.

Williams, G. C. 1957. Pleiotropy, natural selection and the evolution of senescence. Evolution 11: 398-411.

Williams, G. C. 1966a. Natural selection, the cost of reproduction, and a refinement of Lack's principle. American Naturalist 100:687-690.

Williams, G. C. 1966b. Adaptation and Natural Selection. Princeton University Press, Princeton, New Jersey.

Yom-Tov, Y. 1987. The reproductive rates of Australian passerines. Australian Wildlife Research 14:319-330.

Yom-Tov, Y., M. I. Christie, and G. J. Iglesias. 1994. Clutch size in passerines of southern South America. Condor 96:170-177. 